\title{
A equipe de saúde mental numa aproximação sociopoética: das relações interpessoais à produção de subjetividade*
}

\author{
THE MENTAL HEALTH STAFF IN AN SOCIOPOETIC APPROACH: FROM THE \\ INTER-PERSONAL RELATIONSHIPS TO THE PRODUCTION OF SUBJECTIVITY \\ EL EQUIPO DE SALUD MENTAL EN UN ACERCAMIENTO SOCIOPOÉTICO: DE LAS \\ RELACIONES INTERPERSONALES A LA PRODUCCIÓN DE SUBJETIVIDAD
}

\section{Lia Carneiro Silveira', Violante Augusta Batista Braga²}

\begin{abstract}
RESUMO
Objetivamos perceber como se dá a produção de subjetividade dentro dos novos serviços de saúde mental, utilizando como referencial teórico-metodológico uma abordagem inovadora chamada Sociopoética. A produção dos dados deu-se por meio de oficinas com a equipe de trabalhadores de saúde mental de um hospital-dia. Como resultados percebemos aspectos institucionais, sociais, econômicos e pessoais referenciados pela equipe como sendo aqueles mais relevantes na composição do quadro de sua prática dentro dos novos serviços. Concluímos que o processo de pesquisa mostrouse um importante instrumento de auto-análise, permitindo ao grupo repensar sua prática e multiplicar as possibilidades de produção de sentido para suas experiências.
\end{abstract}

\section{DESCRITORES}

Saúde mental.

Pesquisa em enfermagem.

Hospitais-dia.

\begin{abstract}
We aim to notice how the possibilities of subjectivity production are being given inside of the new mental health services using as theoreticalmethodological referential an innovative approach called "Sociopoética". The production of the data was made through workshops with the mental health workers of a Day Unit staff. As a result we noticed the institutional, social, economical and personal aspects related by the group as being the most important aspects that compose the frame of its practice inside of the new services. We concluded that the research process has been an important self-analysis instrument, allowing the group to rethink their practice and multiply the possibilities of sense of production for their experiences.
\end{abstract}

\section{DESCRIPTORS}

Mental health.

Nursing research.

Day Unit.

\section{RESUMEN}

Tuvimos como objetivo percibir cómo se dan las posibilidades de producción de subjetividad dentro de la nueva estructura de salud mental usando como referencial teórico-metodológico una aproximación innovadora llamada Sociopoética. La producción de los datos se hizo a través de talleres con los trabajadores de salud mental de un hospital de día. Como resultados percibimos los aspectos institucionales, sociales, económicos y personales referidos por el grupo como los más importantes en la composición del cuadro de su práctica dentro de los nuevos servicios. Concluimos que el proceso de investigación se mostró como un importante instrumento de auto-análisis, permitiendo al grupo volver a pensar su práctica y multiplicar las posibilidades de producción del sentido para sus experiencias..

\section{DESCRIPTORES}

Salud mental.

Investigación en enfermeria.

Hospitales de dia.

\footnotetext{
* Extraido da Dissertação "Equipe de Saúde Mental: sociopoetizando o Hospital-Dia", Departamento de Enfermagem da Universidade Federal do Ceará (UFC), 2003.

1 Enfermeira. Mestra em Enfermagem. Doutoranda em Enfermagem pelo Programa de PósGradução em Enfermagem do Departamento de Enfermagem da UFC. Bolsista da CAPES. liasilveira@uol.com.br.

2 Enfermeira. Doutora em Enfermagem. Docente do Departamento de Enfermagem da UFC. vivi@ufc.br
} 
Lia Carneiro Silveira

\section{CONTEXTUALIZANDO E PROBLEMATIZANDO}

Vivemos um momento de intensas transformações no campo da assistência em saúde mental. A implementação das propostas da Reforma Psiquiátrica brasileira tem desenhado um cenário rico e fecundo. Sabemos que o real é dinâmico e, por vezes, caótico. É provável, que ao nos debruçarmos sob este panorama, não encontremos uma réplica fiel às propostas idealizadas por tantos sujeitos envolvidos nesse processo: trabalhadores de saúde mental, clientes, familiares e outros setores da sociedade. Por outro lado, a constante mutação do real nos abre infinitas possibilidades de criação e isso é o que nos faz continuar acreditando que é possível construirmos novas formas de pensar e agir perante a loucura.

Entendemos que mudar os muros físicos do manicômio não é suficiente, se isso não vier acompanhado de uma mudança no nosso modo de perceber e, conseqüentemente, agir perante a loucura. De acordo com os pressupostos da psiquiatria democrática italiana, a "produção de vida" é o instrumento dos profissionais de saúde da Reforma Psiquiátrica. Para possibilitarmos essa produção de vida àqueles que assistimos, precisamos, antes de tudo, permitirmo-nos experienciá-la dentro de nós mesmos. Precisamos questionar e descristalizar nossos próprios papéis para que, só assim, possamos abrir espaço para a produção de vida das pessoas em sofrimento mental.

Neste momento de desconstrução/reconstrução da assistência à saúde mental, perguntamos: quais as possibilidades de atuação dos profissionais de saúde dentro dos novos serviços? Entretanto, este questionamento não pode vir separado de um outro intrinsecamente relacionado ao primeiro: que configurações de produção de subjetividade estão ocorrendo nestes espaços? A estreita relação entre estas duas perguntas reside exatamente no fato de não pensarmos a prática social separadamente das formações de subjetividade. Isto porque quando nos referimos à "subjetividade" não estamos falando de um fato psicologizado, individualizado e natural. Falamos, antes, de uma “subjetividade maquínica" a qual não apenas está relacionada com o meio social onde os sujeitos encontram-se inseridos, mas, é responsável, inclusive, por sua produção: o desejo produz o real, ou a produção desejante não é mais do que a produção social ${ }^{(1)}$. Sendo assim, não podemos pensar a prática exercida por estes sujeitos separadamente dos seus próprios mecanismos de produção do desejo, de produção de subjetividade.

Entretanto, um outro cuidado a ser tomado ao mergulharmos nestes espaços destinados a trabalhar a produção de subjetividade é o de evitar desembocar exclusivamente no que chamam de "produção de subjetividade capitalística". Esse é o mecanismo através do qual o capitalismo produz exatamente indivíduos,

indivíduos normalizados, articulados uns aos outros segundo sistemas hierárquicos, sistemas de valores, sistemas de submissão...(2)

Sendo assim, faz-se mister que estejamos a todo o momento atentos para evitar a repetição estéril e o reforço de discursos já instituídos acerca da pratica de saúde mental. Comentam, ainda, que é possível desenvolvermos modos de produção singulares, numa recusa a esta serialização de indivíduos. Este "processo de singularização" leva a construção de uma subjetividade singular através da produção de novos modos de sensibilidade, modos de criatividade e de relação com o outro ${ }^{(2)}$.

Partindo dessa delimitação conceitual, surge uma outra interrogação: como conseguir num processo de pesquisa abordar um processo tão dinâmico como o é a produção desejante? Como conseguir capturar a efervescência que agita os fenômenos moleculares? Ora, se o desejo é processo de produção, não poderíamos aproximarmo-nos do campo de pesquisa em busca de "coletar" dados que já estariam prontos a nossa espera. Precisávamos encontrar um método que nos permitisse mergulhar neste processo sem, no entanto, congelá-lo.

Encontramos na sociopoética os instrumentos necessários para operacionalizar nossos objetivos. De acordo com seu criador a sociopoética

(...) pretende analisar criticamente a realidade social possibilitando trabalhar-se a tranversalidade dos desejos e poderes que agem na vida social(3).

Para que isto seja possível, cabe ao facilitador utilizar-se de dispositivos, ou seja, mon- 
tagens ou artifícios que propiciam o surgimento de inovações, de diferenças, de singularidades. Os dispositivos podem ser caracterizados por um fato, uma pessoa, um tempo, um objeto ou uma tarefa que intervém durante a pesquisa, permitindo multiplicar as respostas e reações já institucionalizadas frente a uma determinada situação ${ }^{(3)}$.

Além da utilização dos dispositivos, a construção do processo de pesquisa, precisa, ainda, seguir alguns princípios para que possamos considerá-la dentro da abordagem Sociopoética. Faz-se necessário valorizar:

(...) a importância do corpo como fonte de conhecimento; a importância das culturas dominadas e de resistência, das categorias e dos conceitos que elas produzem; o papel dos sujeitos pesquisados como co-responsáveis pelos conhecimentos produzidos; o papel da criatividade de tipo artístico no aprender, no conhecer e no pesquisar e a importância do sentido espiritual, humano, das formas e dos conteúdos no processo de construção dos saberes $^{(3)}$.

\section{CONSTRUINDO UM CAMINHAR METODOLÓGICO}

Escolhemos como local para realização do estudo $^{(4)}$ um hospital-dia da rede pública de Fortaleza. Esta escolha deu-se devido ao fato de este ser um dos novos serviços propostos pela reforma psiquiátrica, ter sido um dos primeiros implantados no estado e, ainda, por já termos tido contatos anteriores com a equipe durante supervisão de prática com acadêmicos de enfermagem. O referido hospital-dia foi criado em 1993, em instalações anexas a um hospital de internação psiquiátrica tradicional. Constitui-se num recurso intermediário entre a internação total e o ambulatório e tem por finalidade prestar atendimento a pessoas portadoras de transtornos psicóticos não-orgânicos, na faixa etária de 16 a 60 anos. Oferece atendimento médico, de enfermagem, psicológico, além de atividades expressivas, esportivas, comunitárias, familiares e domiciliares, realizadas de segunda à sexta-feira por uma equipe multidisciplinar. De acordo com documentos fornecidos pela equipe, o objetivo do serviço é favorecer a reestruturação interna do portador de transtorno psicótico não orgânico, possibilitando a melhoria de suas relações sócio-familiares, buscando a diminuição de internações e favorecendo sua reintegração social.

Fizemos contato com a coordenação do hospital-dia para averiguar a disponibilidade dos profissionais para participar da pesquisa, com intuito de formar o "grupo-pesquisador". Na metodologia do grupo-pesquisador, ocorre uma ruptura com o tradicional processo de relação pesquisador/objeto de estudo. Os sujeitos da pesquisa participam desde a escolha do tema a ser pesquisado, seguindo com a produção dos dados até a análise e divulgação dos mesmos, tornando-se

\section{(...) verdadeiros co-pesquisadores, par- ceiros e parceiras dos facilitadores da pesquisa, tanto na construção do conhe- cimento como nas decisões que se deve tomar para que o próprio processo de pesquisa chegue até sua conclusão(3).}

O grupo-pesquisador foi composto por 15 profissionais do hospital-dia, incluindo médico, psicólogo, terapeuta ocupacional, socióloga, auxiliar de terapia ocupacional e auxiliar de enfermagem. Infelizmente não foi possível contarmos com a enfermeira do serviço, pois a mesma se encontrava de licença por ocasião da realização da pesquisa.

Ressaltamos que este estudo foi desenvolvido com a cuidadosa observação das diretrizes e normas regulamentadoras da pesquisa envolvendo seres humanos, Resolução 196/96 do Conselho Nacional de Saúde ${ }^{(5)}$. Foi solicitado o consentimento informado de todos os participantes, e o projeto de pesquisa foi submetido ao Comitê de Ética da Universidade Federal do Ceará.

Os trabalhos foram realizados em forma de oficinas, as quais foram elaboradas procurando-se levar em consideração os princípios da sociopoética, citados anteriormente. Ao todo, foram realizadas oito oficinas sendo uma de negociação, duas de produção dos dados, quatro de análise e uma de encerramento. As oficinas tiveram uma estrutura própria que se repetiu em todos os encontros, como se fosse um ritual, através do qual

\section{(...) criamos um tempo-espaço diferente, com seus próprios ritmos, suas exigên- cias fortes, seus prazeres, diferentes do da vida ordinária(6).}

Outro aspecto importante na ritualização das oficinas reside no fato de que, ao estar
A equipe de saúde mental numa aproximação sociopoética: das relações interpessoais à produção de subjetividade 
Lia Carneiro Silveira Violante Augusta B. Braga em grupo, temos que nos deparar com a imprevisibilidade, com o desconhecido, com respostas as quais não estamos acostumados, tanto dos outro como de nós mesmos. Daí a necessidade de se criar o que Deleuze e Guatarri chamam de "ritornelo". Ou seja, aquilo que delimita um lugar seguro, um mínimo de previsibilidade "(...) é como o esboço de um centro estável e calmo, estabilizador e calmante, no seio do caos"(7). Na pesquisa sociopoética, os ritornelos permitem ao grupo-pesquisador entrar em contato com as forças do caos que começam a surgir.

Cada oficina foi composta de dois momentos: o primeiro deles é dedicado ao relaxamento e o segundo pode ser de produção ou de análise de dados, de acordo com o objetivo da oficina. Esses momentos, entretanto, não são estanques, visto que o próprio relaxamento já é também ocasião de produção de dados. A importância do relaxamento deve-se ao fato de que o grupo-pesquisador deve ser levado a reduzir seu nível de controle consciente a fim de poder multiplicar suas possibilidades de produção de conhecimento ${ }^{(6)}$. Em seguida, ocorre o segundo momento da pesquisa, que pode ser de produção de dados ou de análise.

A proposta inicial de temática sugerida ao grupo foi "produção de subjetividade no hospital-dia". Entretanto, como na proposta da sociopoética o grupo-pesquisador deve ser consultado sobre a relevância do tema a ser pesquisado, aceitamos a proposta do grupo em delimitar a temática inicial e pesquisar o relacionamento interpessoal na equipe. O grupo afirmou ter sugerido este tema, pois a equipe de trabalhadores daquele serviço vinha enfrentando dificuldades no desenvolvimento de seu trabalho e entendia que estes problemas se deviam, basicamente, a fatores de ordem pessoal. Como poderemos perceber posteriormente, esta visão unilateral acabou sendo colocada sob outros prismas e gerando múltiplos aspectos referentes a produção de subjetividade que merecem ser analisados.

Os dados foram compostos por todo o material produzido pelo grupo durante as oficinas, incluindo textos, pinturas, fotos e outras formas de expressão. A técnica utilizada para operacionalizar a produção de dados foi a dos lugares sociomíticos. Inicialmente criada por Gauthier e, posteriormente, utilizada por outros pesquisadores, essa técnica inspira-se nas culturas indígenas do pacífico, as quais pensam em termos de lugares sócio-míticos ${ }^{(8)}$.
A importância de se utilizar técnicas que proponham uma forma de organização do pensamento estranhos àquelas que os membros do grupo estão acostumados, está em podermos propiciar a criação de um princípio incomum, para gerar a expressão da energia imaginativa das pessoas e do grupo. Não estando o grupo acostumado a esta espécie de produção, é provável que emirjam conteúdos, expressões, imagens inesperadas. O objetivo é ver o outro lado da vida, aquele que nossa formação teórica e, mais geralmente, nossa cultura nativa não permite enxergar ${ }^{(6)}$.

Para aplicar a técnica dos lugares sociomíticos, utilizamos um formulário adaptado de uma pesquisa ${ }^{(8)}$, contendo perguntas que os participantes deveriam completar, associando o relacionamento pessoal nessa equipe com diversos lugares sociomítcos como, por exemplo: no relacionamento interpessoal dessa equipe como é a terra onde crescem minhas raízes? O poço onde meu pensamento pode cair? A ponte que me permite sair das dificuldades? Entre outros lugares que ao todo compunham dezesseis perguntas.

Nas oficinas subseqüentes, o grupo-pesquisador analisou os dados produzidos através de textos, pinturas, poesias e expressões verbais. Essas análises exprimem as referências de vida dos membros do grupo (e, às vezes, os referenciais teóricos trazidos por um ou dois deles), permitindo reflexões e interrogações $^{(6)}$. A facilitadora participou desse momento ouvindo sensivelmente a fala do grupo, também analisou os dados, contrapondo sua fala, afirmando sua diferença.

$\mathrm{Na}$ análise sociopoética, identificam-se quatro momentos distintos: o momento viril, o mulheril, o infantil e o filosófico ${ }^{(9)}$. No momento "viril" os dados são estudados de acordo com a lógica dominante do pensamento ocidental segundo o qual devemos dividir, cortar e classificar, em escolhas bem diferenciadas e exclusivas. O momento chamado "mulheril" é absolutamente oposto ao viril, pois

... proporciona passagens, alterações progressivas de um em seu contrário: oferece uma visão geral, ou gosto global dos processos intelectuais em curso no grupo-pesquisador muito desabituado. Fluidez sempre e em todos os lugares. Alterações, transformações, ligações tanto eficientes como secretas ${ }^{(9)}$. 
Em seguida, no momento "filosófico", realizamos uma análise dos dados a partir dos grandes temas da filosofia em nossa cultura. $\mathrm{E}$, finalmente, temos o momento "infantil", onde dispomos os dados em combinações surreais, estranhas ao pensamento do grupo, provocando uma multiplicação das visões sobre o significado dos dados.

Ressaltamos que o nosso processo de pesquisa, enquanto facilitadora do grupo, foi perpassado por todos esse momentos. Não de forma estática, onde poderíamos dizer: "estamos vivendo um momento viril; agora passamos ao mulheril". Inclusive, a palavra "momento", nesse contexto, deve se abster da noção de temporalidade linear. Diríamos que, na verdade, esses momentos são fluxos, que não têm começo nem fim e que, muitas vezes, até se sobrepõem e se misturam dando origem ainda a outros "momentos".

\section{PRODUZINDO A SUBJETIVIDADE: SOCIOPOETIZANDO AS RELAÇÕES INTERPESSOAIS DO GRUPO-PESQUISADOR}

Passamos a descrever as principais análises resultantes dos trabalhos realizados pelo grupo-pesquisador e pela facilitadora, relatadas em forma de um passeio pelos vários lugares sociomíticos que foram trabalhados.

Começamos o percurso e, logo de saída, nos deparamos com o primeiro lugar sociomíticos analisado: a Falha entre Eu e Outro. A falha no sentido geográfico é o plano de separação que se forma entre blocos de uma rocha em conseqüência do deslocamento desta por ocasião dos movimentos tectônicos, ou seja, a falha é a delimitação de um território, marcando onde começa e termina um bloco. Outro detalhe importante é o fato dela ser conseqüência própria do movimento, da mutação de um terreno.

A palavra falha, se aplicada aos seres humanos, pode ter, também, outro significado: omissão, lacuna, falência, defeito (físico ou moral). Por que uma palavra que na natureza significa apenas a conseqüência do movimento natural constante de um terreno foi aplicada aos processos humanos num sentido tão depreciativo? Então as rochas podem transformar-se e os homens não?

A falha-falta é o fantasma que nos persegue: se algo não funciona, com certeza, exis- te um culpado, pois tudo deveria funcionar como um relógio. Acreditando nisso passamos a ser nossos próprios carrascos e os juízes daqueles que estão ao nosso redor. Quando dirigimos o veredicto contra nós mesmos, incorporamos o fantasma da faltafalha em mim. Sofremos com o sentimento de culpa e começamos a acreditar que realmente não somos capazes de inovar, de mudar ou crescer. Marcados pelo estigma da falta, estacionamos: não posso superar a falha, pois sou eu mesmo a causa desta.

Por outro lado, podemos considerar que a culpa é do outro, nunca minha. Num trabalho desenvolvido em equipe são previsíveis as conseqüências de assumir essa posição. Sempre que algo dá errado, a culpa é do outro. Esse "outro" começa a tomar vida numa entidade onipresente, que nunca está em lugar algum, mas que, ao mesmo tempo, está sempre presente. Entretanto, tanto a falhafalta em mim como o falha-falta no outro são filhos da mesma idéia: a de que o mundo é um lugar perfeito e imutável, onde todos têm que se encaixar sem falhas. Mas, se nem mesmo a solidez de uma rocha é constante, como podemos exigir constância no mundo social?

O grupo-pesquisador, ao escolher o relacionamento interpessoal como temática da pesquisa estava restringindo as dificuldades que encontravam no trabalho em equipe a esta única relação de causa e efeito. Através desse raciocínio, o grupo se reconhece culpado pelos problemas enfrentados na equipe, sem, no entanto, levar em consideração a interferência de outros fatores. Esse sentimento de culpa, experienciado constantemente em nossa sociedade, não ocorre por acaso. Pelo contrário, ele é uma função característica da subjetividade capitalística, ao passo que nos mantém em um sentimento de inferioridade e de incapacidade quando nos comparamos aos modelos de identidade que se nos $\operatorname{apresentam}^{(2)}$.

Assim, esse mecanismo de culpabilização, acaba atuando de duas formas. Em primeiro lugar, fazendo com que assumamos como responsabilidade, estritamente pessoal, as falha nos processos de socialização. E, em segundo lugar, faz com que, mesmo que consigamos identificar a exploração, a dominação ou outras agressões, nos sintamos completamente incapazes de ir contra e acabemos pensando que a melhor coisa a fazer é calar. Entretanto, a partir das possibilidades instauradas
A equipe de saúde mental numa aproximação sociopoética: das relações interpessoais à

produção de subjetividade 
Lia Carneiro Silveira Violante Augusta B. Braga no grupo pelos dispositivos, num determinado momento, alguma coisa vazou, havendo uma ruptura. $\mathrm{O}$ grupo foi observando o que estava acontecendo e os conflitos vivenciados no processo de institucionalização da equipe começaram a aparecer.

Enfim, o que era unicausal e unidirecional, começa a se multiplicar em várias direções. As variações já começaram a ser percebidas quando analisamos o lugar sócio-mítico chamado o labirinto onde podemos nos perder. Descobrimos que vivemos constantemente a angústia do "não perder". É como se a vida fosse um jogo no qual estamos sempre competindo e nunca podemos perder: perder tempo, perder dinheiro, perder a paciência. Essa perda não é apenas relativa a fatores externos. É também sentida como algo interno: quando perdemos algo, também nos perdemos. O que importa é ganhar, acumular, obter lucros. Entretanto, muitas vezes estamos tão ocupados em não perder, em nos proteger, em segurar o mundo nas costas, como um Atlas obcecado (É tanta coisa caindo.../ e eu só tenho duas mãos!/ Eu tento segurar tudo/ mas sempre cai algo no chão... Sobra muito pouco espaço para podermos criar algo mais).

O grupo refere que o labirinto onde podem se perder é a falta de preparo profissional. Como a maioria dos membros da equipe foi simplesmente transferida do hospital de internamento tradicional, que funciona em anexo ao hospital-dia, referem não se sentirem suficientemente preparados para desenvolver suas funções. Se sentem frustrados, castrados nas suas potencialidades. Vale ressaltar que esta sensação de impotência e incerteza frente à necessidade de atuar num serviço tipo hospital-dia, não é característica exclusiva desta equipe. Ao colocar em cheque o sistema manicomial e propor a reestruturação dos serviços de saúde mental, a reforma psiquiátrica brasileira exigiu uma outra transformação ainda mais ampla no que diz respeito à nossa forma de atuar perante a experiência da loucura. Outros autores já apontam para as dificuldades inerentes a estas mudanças, pois "trabalhar nessas instituições é se propor um embate cotidiano com a loucura. Tirados os muros concretos, a violência, a objetivação dos internos, nos encontramos diante de sujeitos com sofrimento psíquico intenso e, muitas vezes, sem ferramentas para lidar com a situação" ${ }^{(10)}$. Além disso, a formação acadêmica destes profis- sionais raramente provê as ferramentas necessárias para uma atuação interdisciplinar, criativa e aberta às mudanças.

Ao se deparar com este labirinto o grupo tem duas opções: parar estagnados e perplexos à frente dele, ou, entrar e procurar a saída. Se pararmos, temos a segurança de não correr riscos, mas, também, estamos condenados à inércia. Se entrarmos, corremos o risco de nos perder, mas, as possibilidades de descoberta são inúmeras. Certamente, não saber nunca que caminho seguir é extremamente angustiante. Essa angústia pode, ela também, findar por promover a estagnação. Entretanto, não ter caminhos pré-estabelecidos nos impulsiona a construirmos nossas próprias saídas. E é assim que a equipe tem percebido seu trabalho, como um constante inventar de saídas para as inúmeras dificuldades que surgem no dia-a-dia.

O grupo analisou, também, o lugar sóciomítico chamado o limite onde ficar. Afinal, precisamos mesmo de limites? Somos feitos de matéria em movimento e de um espírito que ronda inquieto buscando sempre algo mais. Somos fluxo, somos continuidade. Mas usar o verbo "ser" aqui só é possível por estarmos separados de alguma forma do resto que nos circula. A pele é um limite, a forma e a distância com que as pessoas se aproximam para iniciar uma conversa é um limite. Constantemente dizemos: "respeite meus limites" ou ainda "a liberdade de um termina onde começam os limites do outro".

Além desses limites físicos e sociais, também criamos limites para delimitar nosso "eu". Precisamos a toda hora de limites sim, mas precisamos mais ainda aprender a transitar entre vários deles. Quando pensamos que encontramos o limite perfeito, ele sempre começa a incomodar. Quando encontramos aquela pele onde nos sentimos "em casa", percebemos que já engordamos ou que ela cedeu e já não nos serve mais. Por que relutamos em trocar de pele? Por que insistem em nos encaixar em modelos pré-moldados de concreto e dizer que aquela é a nossa forma? Por que não se admitem alterações no modelo?

O grupo percebe a dificuldade de lidar com esses limites quando é cobrado a executar suas atividades democraticamente e de forma interdisciplinar, mas, no entanto, ressente-se de uma formação acadêmica verticalizada e individualista. Além do mais, traba- 
lhar democraticamente e em equipe, não costuma ser uma prática nos serviços psiquiátricos tradicionais onde eles desenvolviam suas atividades anteriormente. Surge uma dificuldade em estabelecer papéis, designar competências. Certamente, o incentivo á competitividade e o corporativismo, estimulado pelo modo de produção capitalista, também induzem a uma fragmentação da equipe. Tudo isso acaba por gerar um conflito nos profissionais os quais têm que atuar de uma forma diferente daquela para a qual foram preparados.

Continuando nossa viagem, analisamos o lugar chamado o poço onde nosso pensamento pode cair. Quantas vezes encontramos ou criamos poços na nossa vida? Poços de vaidade, poços de ódio, poços de criatividade, poços de loucura, poços de prazer, poços de vida e poços de nada. Alguns são escuros e nos sugam buraco a dentro, nos digerindo. Outros não têm fundo e nos levam a uma queda infinita. Mas há ainda os poços que se nos oferecem férteis e insinuantes, capazes de regar toda uma produção.

Caminhamos pelas bordas destes poços nos equilibrando numa linha tênue. Às vezes escorregamos e caímos. Noutras, conseguimos nos curvar nessa borda e, com as mãos em concha, juntamos um pouco de líquido e sorvemos. Cair ou equilibrar-se não parece ser a questão, mas sim, a maneira como fazemos uma ou outra coisa. O poço para o grupo-pesquisador é o novo, o desconhecido. Todas as nossas certezas ficam fora de lugar quando adentramos um território novo, com o qual não estamos acostumados. É o caos. Além disso, a equipe de saúde mental ainda tem outra particularidade que contribui para afetar a estabilidade dos profissionais que é o contato com a loucura. $\mathrm{O}$ fato de estar trabalhando num serviço do tipo hospital-dia, cobra uma nova atitude do profissional, pois este não se encontra mais isolado do paciente pelas barreiras físicas e psicológicas impostas no manicômio.

Entretanto, o próprio grupo reconhece que apesar de todas estas dificuldades também pode surgir a criação, a inovação. É aí que o grupo vê o lugar sócio-mítico chamado $c a$ minhos por onde seguir. Nas suas conquistas diárias, nas suas invenções frente ao caos é que o grupo vai construindo um território rico de experiências que merecem ser valorizadas. Como uma rede infinita interligada es- tes caminhos se cruzam, se fundem. A escolha por qual deles seguir é uma mistura de decisões e acaso. Também não são imutáveis, eles se formam e se modificam à medida que caminhamos. A cada passo que damos um novo trecho surge. Bifurcações nos saltam aos olhos por todos os lados: e se ao invés deste caminho tivéssemos tomado aquele? Nunca saberemos. Mas, podemos sim dizer: esse caminho não me serve mais, vou dobrar à direita. (ou à esquerda, ou ainda à outra direção recém-criada). O que vamos encontrar lá também não sabemos, só nos resta andar para ver.

Durante o trajeto encontramos, também, o lugar chamado fluxos que nos atravessam. Fluxos e limites, estados em transição. Se formos só fluxo, não existimos. Se formos só limite, morremos. Afetar e deixar-se afetar, talvez seja essa a tarefa mais difícil que enfrentamos. Criar limites, mas sempre provisórios e tendo o cuidado de deixar frestas por onde passem os fluxos. Muitas vezes o grupo se surpreendeu quando isso aconteceu, pois descobriu potências que nem sequer imaginavam existir. Durante as oficinas os integrantes do grupo pintaram, criaram poesias, textos embora, muitas vezes, nem acreditassem que isso fosse possível.

O grupo caracterizou, ainda, o lugar chamado de ponte que nos permite sair das dificuldades. A ponte une dois pontos, os quais, sem ela, não teriam comunicação. Pessoas, sentimentos, acontecimentos, todos podem ser pontes dependendo do lugar em que estejam, do momento onde aconteçam. Entretanto, nem sempre a saída é uma ponte. Muitas vezes, é exatamente de uma ruptura que precisamos: um movimento, uma palavra, um papel ao vento, os ovos que se quebram e a barata esmagada dos contos de Clarice. A ruptura ocorre e, então, não somos mais os mesmos, tudo muda. Se construirmos ou se destruímos uma ponte não é o mais importante. Desde que do outro lado sejamos mais felizes. O grupo identifica essa ponte como sendo o espaço para poder falar e discutir os problemas. É fortemente destacada a necessidade de uma supervisão institucional, mas este acompanhamento não é oferecido pelo serviço. A equipe ressalta que, sem este acompanhamento sistemático, fica ainda mais difícil superar as dificuldades detectadas.

Para finalizar, o grupo-pesquisador retrata o lugar chamado de terra onde crescem
A equipe de saúde mental numa aproximação sociopoética: das relações interpessoais à

produção de subjetividade 
Lia Carneiro Silveira Violante Augusta B. Braga nossas raizes. Descobrimos que este lugar é uma soma de todos os outros: tem falhas e depressões, tem cumes e elevações; planícies e planaltos, abismos profundos e longos prados. Também tem labirintos e caminhos em linha reta. Vivemos entre os limites desta terra e os fluxos que a perpassam. De vez em quando um poço aqui, uma ponte acolá. Deparamo-nos com tudo isso, é certo. Mas o que faremos com a parte que nos cabe nesse latifúndio?

\section{CONSIDERANDO POSSÍVEIS FINAIS: CONTANDO UM CONTO, AUMENTANDO UM PONTO...}

Quando iniciamos esta pesquisa, levamos ao grupo-pesquisador a sugestão de pesquisarmos a produção de subjetividade no hospital-dia. Após discutirmos esse tema, o grupo sugeriu que o delimitássemos mais e escolheu pesquisar o relacionamento interpessoal na equipe. Ao perguntar o porquê dessa escolha, obtivemos como resposta que alguma coisa não estava funcionando e que eles atribuíam isso a problemas de ordem pessoal fazendo assim, uma espécie de mea culpa.

Foi interessante, a partir daí, observarmos como a viagem pelos lugares sociomíticos foi possibilitando descobrirmos que não era bem assim. Aspectos institucionais, sociais, econômicos e pessoais vieram à tona e compuseram um quadro bem diferente daquilo que existia quando começamos.

O reconhecimento da culpabilização a que estava se submetendo; as conseqüências da divisão técnica e social do trabalho; a polarização entre sujeito produtivo e sujeito individual; a escassa oferta de treinamento para as atividades que exercem; a falta de preparo para desenvolver ações de saúde mental num espaço extra-manicomial; a instabilidade muitas vezes provocada pelo contato com a loucura; a transição entre os modelos de atenção em saúde mental e as dificuldades de trabalhar em equipe quando a formação profissional estimula o individualismo. Estas são algumas descobertas que o grupo fez no decorrer desta viagem.

E quanto à validade da pesquisa em si? Será que, apesar de toda as implicações assumidas durante o processo de pesquisa, foi realmente possível construir algo que fosse válido, se não para qualquer pessoa, pelo menos para o grupo com o qual trabalhamos? Isso, provavelmente, só eles poderão dizer. Apesar destas dúvidas, entretanto, conseguimos identificar algumas peculiaridades deste estudo que certamente constituem, em si mesmas, vantagens para o grupo-pesquisador e para a construção do conhecimento na prática de saúde mental.

Em primeiro lugar, entendemos que foi possível identificar fatores que interferem nas possibilidades de construção da prática da assistência ao indivíduo em sofrimento mental dentro dos novos serviços. O grupopesquisador, no desenrolar das oficinas, soube mostrar como esse processo está acontecendo na sua realidade. Logicamente não é um resultado generalizável. Em cada serviço, em cada equipe, em cada momento, iremos encontrar realidades diferentes.

Percebemos, também, que o próprio processo de pesquisa mostrou-se para o grupo um importante instrumento para que eles pudessem realizar uma auto-análise de sua prática. O grupo-pesquisador deixou evidente a importância de espaços para discussão. Entendemos que esta foi a principal contribuição desta pesquisa para a equipe de saúde mental. No entanto, ainda é pouco. Para que a equipe pudesse trabalhar os processos institucionais; os afetos que o trabalho interdisciplinar e o contato com a loucura provocam e as tecnologias de controle enxertadas pelo processo de socialização faz-se necessário que a auto-análise seja realizada continuamente.

Com relação a nossa experiência como facilitadora de uma pesquisa sociopoética, ressaltamos que o universo com o qual entramos em contato durante a realização deste estudo desencadeou inúmeros afetos que, apesar de não poderem ser classificados, merecem ser destacados. Como exemplo, gostaríamos de comentar as conseqüências de abandonar a capa da neutralidade e da objetividade ao realizar uma pesquisa; de utilizar um arcabouço teórico que permita perguntar, a nós mesmos, o porquê da escolha do tema; explorar que condições nos levaram a tomar determinado caminho e, inclusive, passar para as páginas que escrevemos as angústias e alegrias de se mergulhar numa verdadeira viagem ao fora. Os efeitos produzidos pelo encontro com a esquizoanálise e com a sociopoética foram, sem dúvida nenhuma, uma experiência revolucionária em todos os aspectos. 
É importante destacar, também, algumas singularidades relativas à relação orientadora/ orientanda ao se utilizar uma metodologia sociopoética. Por seu caráter inovador e desestruturador de muitas verdades já instituídas no meio acadêmico, a sociopoética exige mais audácia, mais coragem de arriscar. Essa relação, também, é facilitada pela própria liberdade que o referencial nos dá de discutir abertamente com a orientadora todas as nossas idéias, medos e resistências.

Por último, mas não menos importante, gostaríamos de ressaltar a importância, para a enfermagem, de metodologias que estimulem a criatividade, a análise das implicações e a abordagem da subjetividade, enquanto processo. Trabalhamos, a todo o momento, com corpos. Não só corpos físicos, mas também, afetivos, libidinais, entre outros. O que faremos desses contatos é uma questão, acima de tudo, ética, pois, não acreditamos em imparcialidade. Não assumir uma postura é, ao mesmo tempo, concordar com a exploração e dominação daqueles que nos entregam suas vidas. Na pesquisa ou na assistência, despertar potências e promover a criação de territórios habitáveis, essa deve ser a tarefa do profissional comprometido com a produção de vida daqueles a quem assistimos. Certamente não é tarefa fácil. Despir-se daquilo que, por muito tempo, acostumamos chamar de "verdade", exige muito mais de nós. Mas,

Na sede de nascer de novo

Dia faz sofrer. De lá será

Partida, pra longe de mim mesmo

Assim, preciso do ar

Desse indivíduo ar, criar.

Agora tenho nova mente

Quem diria a mesma?

Perdi verdades, vermelhosidades,

Azuliberdades e branquigualdades.

O que ficou é não ficar no mesmo

Lugar assim, preciso do ar...

Desindividuar(4)
A equipe de saúde mental numa aproximação sociopoética: das relações interpessoais à

produção de subjetividade

\section{REFERÊNCIAS}

(1) Deleuze G, Guattari F. O anti-Édipo: capitalismo e esquizofrenia. Lisboa: Assírio \& Alvim; 1968.

(2) Guattari F, Rolnik S. Micropolítica: cartografias do desejo. $5^{\text {a }}$ ed. Petrópolis: Vozes; 1999.

(3) Gauthier JHM. Sociopoética: encontro entre arte, ciência e democracia na pesquisa em ciências humanas e sociais enfermagem e educação. Rio de janeiro: Escola de Enfermagem Ana Nery da UFRJ; 1999.

(4) Silveira LC. Equipe de saúde mental: sociopoetizando o hospital-dia. [dissertação] Fortaleza (CE): Universidade Federal do Ceará; 2001.

(5) Conselho Nacional de Saúde. Resolução n. 196, de 10 de outubro de 1996. Diretrizes e normas regulamentadoras de pesquisas envolvendo seres humanos. Inform Epidemiol SUS 1996; $6: 12-41$.
(6) Gauthier JHM. O que é sociopoética. São Paulo: Brasiliense; 1999. (Coleção Primeiros Passos).

(7) Deleuze G, Guattari F. Mil platôs: capitalismo e esquizofrenia. Rio de Janeiro: Editora 34; 1997. v. 4.

(8) Gauthier JHM, Santos I. Enfermagem: análise institucional e sociopoética. Rio de Janeiro: Escola de Enfermagem Ana Nery da UFRJ; 1999.

(9) Gauthier JHM, Santos I, Souza LS, Figueiredo NMA. A sociopoética: uma filosofia diferente e prazerosa. In: Gauthier JHM, Cabral IE, Santos I, Tavares CMM, organizadores. Pesquisa em enfermagem: novas metodologias aplicadas. Rio de Janeiro: Guanabara Koogan; 1998. p. 122-76.

(10) Lima AE. Habitando um paradoxo. Cad Subjet 1996; 4(1):162-75.
Correspondência para: Lia Carneiro Silveira Av. Barão de Studart, 1891 - Ap. 304 - BI.A - Aldeota Fortaleza -

CEP - 60120-001 - CE 